\title{
El ojo de Polifemo ${ }^{1}$
}

En principio es necesario desviarse del todo, extraviarse y no mirar de frente la experiencia. Porque sólo puede verse verdaderamente aquello que la vista no fija, aquello que domina borrosamente al ojo y no lo que el ojo apacigua al distinguirlo en su foco.

Francisco Segovia

Ya desde la Odisea encontramos una prueba de ese horror al vacío que preña los mundos regidos por un solo ojo, los mundos bucólicos. ${ }^{2}$ Polifemo, el gigante con un ojo grande en medio de la frente, es aniquilado por el vacío, ya que Ulises, que lo enceguece, se presenta a él como "Nadie". Adorno y Horkheimer han hecho notar la pertenencia de Polifemo y los

1 Este trabajo forma parte de un estudio sobre la idea del parafso en la novela bucólica del Renacimiento, actualmente en preparación. Para la mejor inteligencia del articulo, y especialmente de su primera frase, conviene decir que la representación idflica de la naturaleza, característica del género bucólico, o pastoril, se emparenta con la que conocemos en pintura con el nombre de "paisaje", puesto que se trata de una representación que descansa sobre un punto de vista panorámico de las cosas, sosegado y sin profundidad, justamente como si se mirara la naturaleza a través de un ojo único, central y distante, y no de dos ojos juntos, alerta y en movimiento.

2 En la raiz de la palabra 'bucólico' hay' una clara resonancia, a través de la ráiz 'buco' (bucca) de la palabra "boca", y Corominas señala en efecto que una deformación o derivación usual del término 'bucólico' es el que se emparenta a partír del siglo xyI con el significado de "comida". A su vez, el ojo único, como lo han señalado Adorno $y$ Horkheimer, no es más que un agujero sustitutivo de la boca ('buco', en italiano, quiere decir justamente hoyo, agujero). Así, en el término 'bucólico' confluyen por un lado los significados de boca y comida (y por otras derivaciones, los de concavidad y bolsa; ver bucosidad: capacidad de un buque), y por el otro, el de una visión unívoca (el ojo único), propia de la actividad vigilante de los pastores o boyeros. 
otros cíclopes a un mundo primitivo de la abundancia, es decir bucólico. ${ }^{3}$ Para ello se han basado en las palabras de Homero en el canto Ix de la Odisea:

Desde alli continuamos la navegación con ánimo afligido, y llegamos a la tierra de los cíclopes soberbios y sin ley; quienes, confiados en los dioses inmortales, no plantan árboles, ni labran los campos, sino que todo les nace sin semilla y sin arada [...] y se lo hace crecer la lluvia enviada por Zeus. ${ }^{4}$

La gran cueva de Polifemo, en la que penetran sigilosamente Ulises y los suyos mientras el gigante está apacentando sus ovejas, se encuentra óptimamente abastecida y ordenada como la morada de un granjero. Los establos rebosan de corderos y cabritos, los mayores separados de los medianos y éstos de los recentales; hay en todas partes zarzos cargados de queso y el suero gotea de las vasijas que el cíclope utiliza para ordeñar. En el Ciclope de Eurípides, el único drama satírico del teatro griego que ha llegado completo hasta nosotros, este bienestar es directamente proporcional a la estupidez y el cinismo del gigante:

Comer, beber, dia tras dia. ¿Para qué hace falta Zeus? [...] ¿Los dioses? QQué dioses! A nadie ofrendo yo oblaciones. Mira cuál es mi mayor dios: jesta pancita linda!

El ojo único de Polifemo se relaciona así con una época de abundancia anterior a la agricultura, a las leyes y a la religión. Como afirman Adorno y Horkheimer, el ojo único constituye un signo mismo de la prehistoria, puesto que recuerda la nariz y la boca, más primitivos que la simetría de los ojos, y esa simetría es lo único que llega a proporcionarnos, a través de la unidad de dos percepciones convergentes, las experiencias de la identificación, de la profundidad y la objetividad.

3 Adorno, T. y Horkheimer, M. Dialéclica del iluminismo, Buenos Aires, Sur, 1970.

4 Homero, La Odisea, trad, de Luis Segala y Estalella, México, Porrúa, Col. "Sepan Cuántos" 1973. 
Hay un pequeño detalle en el texto de Homero, no señalado por Adorno y Horkheimer, que confirma la condena de los cíclopes a un mundo sin profundidad, unifocal y subjetivo (aunque más que de condena habría que hablar de una adhesión natural e inevitable). Ulises y los suyos no desembarcan directamente en la tierra de los cíclopes sino en una pequeña isla que se halla a poca distancia del litoral. Ulises la describe como una isleta deshabitada, con una infinidad de cabras monteses, poblada de bosques, cuyo terreno, por carecer de habitantes, está siempre sin arar ni sembrar. Los cíclopes no pueden habitarla por la sencilla razón de que no tienen manera de trasladarse por mar, pues carecen de barcos y desconocen el arte de construirlos. La isleta, explica Ulises, los recompensaría grandemente si pudieran colonizarla, puesto que es muy fértil y daría a su tiempo frutos de toda especie, incluida. la vid, y por ser el suelo muy pingüe podrían obtenerse mieses altísimas en la estación oportuna. Por si fuera poco, esta isleta tienen un cómodo puerto, donde no se requieren amarras, ni es preciso echar áncoras, ni atar cuerdas, tan abrigado se halla de los elementos. $Y$ en lo alto del puerto, concluye Ulises, debajo de una nueva alrededor de la cual han crecido álamos, mana una fuente de agua límpida.

Se trata en suma de un clásico parąe bucólico, virgen, no. hollado por los hombres, dadivoso y fértil, con una fuente de agua y un puerto acogedor y tranquilo. No obstante estar tan a la mano, "delante del puerto, no muy cerca pero tampoco a gran distancia de la región de los cíclopes", éstos, que carecen de embarcaciones, no pueden sacarle ningún provecho. Así, la isleta, abandonadla a sí misma, aparece como un sitio neutro, intangible y fuera del tiempo. Los cíclopes, puesto que no pueden alcanzarla (pues ella representaría sin duda la primera etapa de cualquiera de sus travesías), muestran su incapacidad de expanderse en el mundo. ¿Qué es en efecto esa isleta sino el natural trampolín desde el cual el mundo podría tornarse accesible y familiar, la plataforma que les permitiría salir y volverse verdaderamente aduitos, capaces de enfrentarse a la 
escasez extexior? En cierto modo, la conquista de toda madurez supone siempre la existencia de una "isleta" intermedia entre el mundo y nosotros, un punto firme donde apoyar el pie para dar el salto hacia adelante. Esta isleta puede ser un maestro, un amante, un libro, un viaje, un incidente o una enfermedad. Como sea, tendrá siempre el carácter de un conducto iniciático y como tal tendrá también el carácter ambivalente de la isleta homérica: fértil pero al mismo tiempo despoblada, pingüe pero también árida, segura pero también efímera. Por eso no es casual su posición equilibrada y central ("delante del puerto, no muy cerca pero tampoco a gran distancia de la región de los cíclopes"), pues se trata en el fondo de un lugar en blanco, no de una meta sino de un comienzo, y es precisamente en este sentido que podemos verla como la metáfora exacta de ese punto neutro, separado de los ojos pero no lejano de ellos, en donde convergen las dos señales visuales que dan cuerpo a la bifocalidad. Puesto que no pueden o no quieren alcanzar la isleta, los cíclopes no pueden tampoco emanciparse de su único ojo, es decir de esa visión infantil y unifocal que tienen del mundo (de esa etapa "oral", diría un psicoanalista atendiendo a la relación propuesta por Adorno y Horkheimer entre el ojo único y la boca), que es, de paso, lo que le permite a Ulises llevar a cabo su famosa treta contra Polifemo presentándose con el nombre de "Nadie" y, con ello, salvar su vida y la de sus compañeros.

La treta de Ulises, en efecto, muestra claramente las limitaciones del mundo de los cíclopes. Puesto que no han alcanzado nunca la isleta despoblada, los cíclopes desconocen, entre otras cosas, la experiencia del regreso, de la vuelta a casa. No conocen, por consiguiente, la experiencia del desdoblamiento, que está presente en todos los regresos bajo la forma implícita: "Este que regresa es el mismo y es diferente de aquel que se fue. Esta tierra es la misma y es otra." Así, los cíclopes no pueden, o no quieren, mirarse a sí mismos. Privados de la virtud del desdoblamiento, ese desdoblamiento que ganarían Ilegando a la isleta (no sólo porque ésta es quieta e intangible 
como un espejo, sino porque desde ahí podrían ver por primera vez su propia tierra), desconocen también la capacidad fundamental del lenguaje de replegarse sobre sí mismo, o sea de reiterar y redundar, de dar forma a analogías y traducciones, de crear ambigüedad y dobles sentidos. De hecho, el carácter mutable y relativo de la realidad es la primera enseñanza que se obtiene de cualquier regreso, y nadie lo sabe mejor que Ulises, el héroe del retorno, que viaja a contrapelo y discieme la faz de las cosas que en la ida no pudo ver. Los cíclopes, en cambio, se han perdido irremediablemente de esa lección. Puesto que no conocen el regreso, que todo lo relativiza, ven la realidad perpetuamente de ida, congelada en una eterna "primera vez". De ahí que Polifemo se ría de Ulises cuando éste le recuerda las sagradas reglas de la hospitalidad. ¿Qué valor pueden tener estas reglas para quienes viven en un eterno presente sin expectativas, cuyo ojo central y telescópico los obliga a una visión unívoca y frontal del mundo, sin reveses ni futuro, fiel en todo y por todo a la naturaleza benigna y petrificada en la que viven?

En su célebre ensayo sobre la afasia, Román Jakobson afirma que una de las variantes principales de los trastomos afásicos, la variante que él llama "afasia por sustitución deficiente" (o también "por trastorno de la semejanza"), se caracteriza por una marcada aversión hacia la redundancia. Los pacientes son incapaces, por ejemplo, de nombrar un objeto que tienen a la vista, ya que si se les dice "esto es un lápiz" al tiempo que se les señala el lápiz, sienten que están meramente duplicando un signo, o sea que están produciendo una redundancia inútil. De la misma manera, se niegan a formular una predicación cualquiera que tenga forma ecuacional, a descloblar (duplicar) un mismo significado en dos o más exprẹsiones distintas, como cuando se dice: "El soltero es un hombre que no está casado", o "Asia es un continente"." Esta aversión hacia la redundancia, prosigue Jakobson, delata en realidad una aversión

- Jakobson, R., "Dos aspectos del lenguaje y dos tipos de trastornos afásicos" en Jakobson y Mall, Fundamentos del lenguaje, Madrid, Ayuso, 1974. 
más general hacia cualquier operación de tipo metalingüístico, es decir aquellas operaciones en donde el lenguaje de algún modo se repliega sobre sí mismo, como son la traducción, la paráfrasis, las circunlocuciones, las analogías, la repetición de palabras, etc.

Estos afásicos rechazan también la homonimia y la sinonimia, ya que las dos implican la redundancia del significante y del significado respectivamente. Es claro que si llevamos más lejos las premisas de Jakobson tendremos que concluir que la única forma verdaderamente segura de no redundar, o sea de no incurrir en repeticiones de ningún tipo, es la de poseer una palabra por cada ser de la realidad. Ya no se utilizaría la palabra 'árbol' para todos los árboles del planeta sino una palabra distinta por cada árbol existente; sería una lengua de puros nombres propios, de pura designación. Así sucecle en el caso, citado por Jakobson, de una mujer afásica que daba sus nombres a los colores fundamentales - rojo, azul, verde y amarillo- pero se negaba a llamar así a los tonos intermedios puesto que para ella las palabras no eran capaces de asumir significados derivados adicionales por semejanza con su significado original, o el de otro afásico que se rehusaba a aceptar los diferentes usos del cuchillo, y por eso nunca pronunciaba la palabra 'cuchillo' sola, sino que, según su uso y las circunstancias, llamaba al cuchillo alternativamente 'cortaplumas', 'mondador', 'cuchillo de pan', etc., es decir que se rehusaba a reunir en un solo concepto significaciones diferentes. He subrayado la palabra derivados puesto que por los ejemplos dados por Jakobson parece evidente que este tipo de afásicos, lesionados en su facultad de percibir semejanzas y analogías, o en su facuitad de expresarlas, se hallan sobre todo incapacitados para derivar una cosa de otra, como si dijéramos que no logran hallar denominadores comunes y por eso no pueden reunir cosas y conceptos disímiles. Como no pueden afirmar nunca "esta cosa es tal otra", son incapaces de realizar cualquier traducción, entendienclo por traducción la operación verbal a tra- 
vés de la cual se establece una equivalencia entre significados semejantes pero no idénticos.

Ahora bien, este deseo inconsciente de poseer una palabra por cada ser de la realidad ${ }^{6}$ delata otro deseo mayor: el de poseer una realidad estática y eterna, despejada de semejanzas internas y confusiones.

Estos afásicos rechazan también la homonimia y la sinonivible y dado de una vez para siempre le sugiere a Ulises su treta contra Polifemo. Ulises adivina que esos seres con un solo ojo, que todo lo ven en el sentido unívoco de la ida -es decir, en el sentido de lo que es abundante e imperecedero-son demasiado autocomplacientes y perezosos ("soberbios y sin ley" los define desde el comienzo) para rebajarse a aceptar la ambigüedad intrínseca del mundo y reconocer que todo es relativo. Precisamente el error de Polifemo consiste en creer que todo, a lo largo y lo ancho de la tierra, ha de tener las dimensiones del mundo de los cíclopes; por eso, ante el escaso tamaño de Ulises y los suyos, los juzga inofensivos. De este error se arrepentirá más tarcle:

jOh dioses! Cumpliéronse los antiguos pronósticos. Hubo aquí un adivino excelente y grande, Telémaco Aurimida, el cual me vaticinó lo que hoy sucede: que sería privado de la vista por mano de Odiseo. Mas esperaba yo que llegase un varón de gran estatura, gallardo, de mucha fuerza; y es un hombre pequeño, despreciable y menguado quien me cegó el ojo, subyugándome con el vino.

(Canto Ix, $507 y^{\prime}$ ss.)

Este "provincianismo" que le cuesta el ojo a Polifemo es el mismo que encontramos en aquel afásico citado por Jakobson que, puesto delante de un lápiz, lleno de una fe ciega en la solidez e inalterabiliclad de la naturaleza, juzga como una redundancia superflua $-y$ tal vez como una secreța usurpación-

c Fabría que preguntarse si no cs precisamente esto Jo que se encuentra en in base del significado etimológico del nombre Polifemo: el de las muchas voces y palabras. 
el acto de desdoblar el dato empírico que se le presenta en su equivalente verbal. Podemos pues reconstruir en sus trazos generales la intuición de Ulises. Ulises se da cuenta cle que los cíclopes no han podido siquiera desdoblar su vista en clos ojos disímiles y que por lo tanto son incapaces del acto de traducción o ecuación más primario de la mente, aquel que crea un punto de convergencia medio entre dos percepciones dispares: de ello deduce que Polifemo no podrá construir alrededor de un nombre ficticio ("Nadie") una mínima predica-ción ecuacional que haga entender a los demás cíclopes que "Nadie es un hombre que acaba de herirme", frase equivalente a "Nadie no es un pronombre indefinido sino el hombre que acaba de perforarme el ojo". Intuye, en definitiva, que los ciclopes no tienen manera de explicar o entender la redundancia, y concretamente la homonimia, puesto que su ciega fe en una realidad pletórica e indeteriorable les impide concebir algo que pueda presentarse con una apariencia ambigua y polivalente.

No es casual que el disparador de esta "desilusión" que padece Polifemo sea el vino. Aunque conocen la vid, Homero presenta a los cíclopes como consumidores de leche. Por lo menos las dos o tres comidas que se prepara Polifemo dentro de la cueva están rociadas con abundante leche, excepto la última, cuando probará extasiado de manos de Ulises el fuerte vino que éste recibió en regalo de Manón, sacerdote de Apolo. Eurípides, en su Ciclope, convertirá a Polifemo y sus congéneres en unos desconocedores totales del vino, acentuando así resa dicotomía entre el vino y la leche que es uno de los ingre-dientes del drama de Polifemo. Recordemos una vez más lo que escribió Roland Barthes sobre esta dicotomía: " $\mathrm{El}$ vino .es mutilante, quirúrgico: trasmuta y engendra; la leche es cosmética: liga, recubre, restaura". Ulises, el mutilador de Polifemo, el que trae a la tierra de los cíclopes la dura verdad de que todo es dudoso y relativo, es también el que trae el vino. Desde siempre, el vino se alía a lo que es doble y ambiguo: "ver doble" es una de las expresiones clásicas para describir 
sus efectos. Ver doble, o sea, entre otras cosas, verse a sí mismo, desdoblarse para conocerse. El vino pertenece al regreso, a la faz escondida de las cosas, a las vísceras y a la vuelta a casa. La leche pertenece al mundo ciclópeo e infantil de la ida, de la rectitud y de la abundancia: a un mundo anterior y más primitivo. En este sențito los cíclopes representan, para. Adorno y Horkheimer, la edad bárbara de los pastores y cazadores. Recordemos una vez más las palabras de Homero: "No. tienen ágoras donde se reúnan para deliberar ni leyes tampoco, sino que viven en las cumbres de los altos montes, dentro. de excavadas cuevas". La abundancia, comentan Adorno y Horkheimer, no necesita de leyes. Tampoco necesita, añadimos nosotros, de la objetividad y la profundidad, o sea de los. dos ojos; porque si es una abundancia auténtica, todo lo aproxima al hombre y le deja los frutos al alcance de la mano. Lo. que necesita la abundancia, o mejor dicho, lo que hace falta. en un reino de la abundancia, es sólo una cosa: precisión, esa precisión que resalta el objeto al separarlo de su entorno, facilitando su captura. Ahí está como prueba el cazador, el hombre que cierra un ojo para afinar la puntería. Lo que está haciendo es depurar su campo visual de todo lo que sea su presa, emancipar la presa de esa vasta profundidad en que se halla inmersa, convertirla en una silueta de contornos precisos, divorciada de todo lo que la rodea: la transforma en un blanco, esto es, pone en blanco la naturaleza. Y esto lo hace en el momento inmediatamente anterior a la captura, cuando la presa está cerca, y no antes, durante la fatigosa búsqueda. Los cíclopes, con su único ojo en medio de la frente, son: pues los cazadores "del último instante", los cazadores "un momento antes del disparo", perpetuamente próximos a la presa. Lo que los separa de la dicha es sólo un destello, un respiro. El horror al vacío, a equivocarse, a disparar fuera del blanco, deteriora en el último instante la sensación de estar a un paso de la plenitud. La historia de Polifemo puede reducirse al horror que suscita la sorpresiva presencia de un "nadie", de un hueco, en nuestra colmada y satisfecha visión de 
la vida. Para reintegrar el vacío a la vida y para soportarlo, sólo queda un remedio, abrir otro ojo junto al ojo original: el ojo crítico, el ojo del regreso, el ojo de la ironía y de la profundidad, el ojo, pues, de la aceptada pérdida del paraíso. 